\title{
Identification and Characterization of Alkaline Protease Producing Bacillus firmus Species EMBS023 by 16S rRNA Gene Sequencing
}

\author{
Rohan wishard ${ }^{1}$, Mahak Jaiswal ${ }^{1}$, Maheshwari Parveda ${ }^{2}$, Amareshwari $\mathrm{P}^{2}$, Sneha Singh Bhadoriya ${ }^{1}$, \\ Pragya Rathore ${ }^{3}$, Mukesh Yadav ${ }^{1}$, Anuraj Nayarisseri ${ }^{1 *}$, Achuthsankar S. Nair ${ }^{2}$ \\ ${ }^{1}$ (In silico Research Laboratory, Eminent Biosciences, Indore 452010, India) \\ ${ }^{2}$ (Dept. of Genetics, Osmania University, Hyderabad 500075, India) \\ ${ }^{3}$ (Dept. of Biotechnology, Sanghvi Institute of Management \& Science, Indore 453331, India) \\ ${ }^{4}$ (Department of Computational Biology \& Bioinformatics, North Campus, Kariavattom, University of Kerala, \\ Thiruvananthapuram, Kerala 695581, India)
}

Erratum to Interdiscip Sci Comput Life Sci (2014) 6: 271-278

DOI: $10.1007 / \mathrm{s} 12539-014-0187-\mathrm{z}$

The original version of this article unfortunately contained some mistakes:

Rohan wishard should be Rohan Wishard;

The last author Achuthsankar S. Nair belongs to the $4^{\text {th }}$ affiliation;

In Abstract, first line, the word 'eßect' should be changed to 'effect'.

The online version of the original article can be found at

http://link.springer.com/article/10.1007\%2Fs12539-014-0187-z

\footnotetext{
*Corresponding author.

E-mail: anuraj@eminentbio.com
} 